\title{
Tackling obesity in the Eastern Mediterranean Region
}

\author{
Citation: Tackling obesity in the Eastern Mediterranean Region. East Mediterr Health J. 2019;25(2):142-143 https://doi.org/10.26719/2019.25.2.142
}

Copyright ( ) World Health Organization (WHO) 2019. Some rights reserved. This work is available under the CC BY-NC-SA 3.0 IGO license (https:// creativecommons.org/licenses/by-nc-sa/3.o/igo).

\section{Introduction}

The World Health Organization (WHO) Eastern Mediterranean Region has experienced epidemiological and nutritional transitions that have contributed to high rates of overweight and obesity within the Region. Half the Region's adult women (50.1\%) and more than two in five men $(43.8 \%)$ were overweight or obese in 2014 (1). The rates of overweight or obesity among the Region's children are higher than the global average of $7 \%$, and in some countries more than $15 \%$ of children are affected (1). In many countries in the Region, more than half of adolescents were reported to be overweight or obese (1). The consequences for the health and well-being of the population are serious, and the social and economic case for investing in prevention of overweight and obesity is clear.

The WHO Regional Office for the Eastern Mediterranean supports the implementation of national strategies and action plans to address overweight and obesity. Countries have struggled, however, to implement multi-sectoral policies or interventions to tackle this major challenge. In 2016, therefore, a process was initiated to assess the situation, identify key challenges and gaps, and come up with a series of proposals on priority areas for action to prevent obesity.

A new regional framework for action on obesity prevention (2019-2023) (2) was endorsed by the 65th session of the Regional Committee for the Eastern Mediterranean in October 2018 (3). A regional meeting to present the regional framework and discuss the promotion of its implementation was held at the University of Sharjah, United Arab Emirates on 26 November 2018 (4). The meeting was held alongside the Seventh Regional Sehati Conference and was cohosted by the Federal Ministry of Health of the United Arab Emirates, the University of Sharjah and the City of Sharjah, under the patronage or Her Highness Sheikha Jawaher Bint Mohammed Al Qasimi, wife of His Highness the Ruler of Sharjah and Chairperson of the Supreme Council for Family Affairs. The regional meeting was attended by 45 participants, including nutrition focal points of 12 countries, external experts and members of the WHO Secretariat.

The objectives of the meeting were to:

- encourage Member States to engage in active coordination for the implementation of the UN Decade on
Nutrition (5), aiming to identify solutions and good practices to tackle obesity;

- share policies, programmes and plans to address overweight and obesity; and

- launch the regional framework for action on obesity prevention and a new regional report on implementation of policies on restricting marketing of unhealthy foods to children.

\section{Summary of discussions}

The 10 recommended areas for action in four domains (regulatory action, prevention, obesity management and treatment, and surveillance) of the new regional framework were presented to participants. There is substantial and growing evidence to support these recommendations and lessons to be drawn from the experience of implementing countries, both within the Region and elsewhere. Presentations were made describing experiences in implementing national obesity strategies, taxing soft drinks, restricting marketing of unhealthy food to children, front-of-pack nutrition labelling, and food product reformulation in European countries.

Countries were made clear on what needs to be done to tackle obesity, but they would like more guidance and support on how to implement and scale-up these actions. There was a call to draw on the lessons from experience with tobacco control and the approaches applied through the WHO Framework Convention on Tobacco Control (FCTC) (6).

The Organization has a number of initiatives underway, to support countries in these efforts. For example: new global guiding principles and a regional technical roadmap for implementation of front-ofpack nutrition labelling; step-by-step guidance on implementation of the WHO set of recommendations on marketing of foods and non-alcoholic beverages to children in the Region; establishment of a regional nutrition network to facilitate exchange and sharing of technical support and best practice; and development of a new 10-year regional nutrition strategy to guide efforts to tackle all forms of malnutrition, including overweight and obesity, within the framework of the UN Decade of Action on Nutrition.

The meeting concluded with signing the Sharjah Declaration on Obesity Prevention, in which signatories renewed their commitment to tackling obesity, through

This report is extracted from the Summary report on the Regional meeting on tackling obesity in the Eastern Mediterranean Region with more focus on healthy diet, Sharjah, United Arab Emirates, 26 November 2018 (http://applications.emro.who.int/docs/EMROPUB_2019_EN_22290.pdf?ua=1). 
the new regional framework on obesity prevention, and accelerating progress towards achieving the targets of the Sustainable Development Goals to reduce premature mortality from non-communicable diseases by one third by 2030 and end all forms of malnutrition by 2030 .

\section{Recommendations}

1. Facilitating sharing of knowledge, experience and good practice. This could include establishing platforms/websites/social media groups and e-learning tools for dissemination and exchange, organization of country field visits, and other actions to foster intercountry collaboration.

2. Providing technical guidance on a range of issues, including: how to tackle cross-border marketing; standardizing portion sizes; designing taxes for high fat or sugar foods and meals; training materials for health professionals; infant and young child feeding resources; and prioritizing nutrition-related research needs.

3. Supporting advocacy and building political will by, for example, generating economic data to make the investment case for action, producing "score cards" to assess and compare country progress, organizing high-level meetings and producing advocacy materials to help decision-makers respond to opposition from vested interests.

4. Supporting data collection for surveillance and monitoring progress, including for national nutrition surveys, and providing an implementation framework for monitoring and evaluating interventions and guidance on data collection at the subnational level.

\section{References}

1. World Health Organization Regional Office for the Eastern Mediterranean. Proposed policy priorities for preventing obesity and diabetes in the Eastern Mediterranean Region. Cairo: World Health Organization Regional Office for the Eastern Mediterranean; 2017 (http://applications.emro.who.int/docs/emropub_2017_20141.pdf?ua=1\&ua=1).

2. World Health Organization Regional Office for the Eastern Mediterranean. Promoting health and well-being: executive summary (EM/RC65/6 Rev.1). Cairo: World Health Organization Regional Office for the Eastern Mediterranean; 2018 (http://applications. emro.who.int/docs/RC_Technical_Papers_2018_6_20540_EN.pdf?ua=1).

3. World Health Organization Regional Office for the Eastern Mediterranean. The 65th Session of WHO's Regional Committee for the Eastern Mediterranean concludes in Khartoum calling for solidarity and Health for All by All. Cairo: World Health Organization Regional Office for the Eastern Mediterranean; 2018 (http://www.emro.who.int/media/news/the-65th-session-of-whos-regional-committee-for-the-eastern-mediterranean-concludes-in-khartoum-calling-health-for-all-by-all.html).

4. Regional meeting on tackling obesity in the Eastern Mediterranean Region, Sharjah, United Arab Emirates, 26 November 2018 (http://applications.emro.who.int/docs/EMROPUB_2019_EN_22290.pdf?ua=1).

5. United Nations System Standing Committee on Nutrition. The UN decade of action on nutrition 2016-2025. New York: United Nations; 2016 (https://www.unscn.org/en/topics/un-decade-of-action-on-nutrition).

6. World Health Organization. WHO Framework Convention on Tobacco Control. Geneva: World Health Organization; 2003 (https://www.who.int/fctc/text_download/en/). 